\title{
Determination of Potassium, Sodium, and Total Alkalies in Portland Cement, Fly Ash, Admixtures, and Water of Concrete by a Simple Flow Injection Flame Photometric System
}

\author{
Jaroon Junsomboon ${ }^{1}$ and Jaroon Jakmunee ${ }^{2}$ \\ ${ }^{1}$ Physics and Engineering 2 Sub-Division, Physics and Engineering Program, Department of Science Service, \\ Ministry of Science and Technology, Bangkok 10400, Thailand \\ ${ }^{2}$ Department of Chemistry and Center of Excellence for Innovation in Chemistry, Faculty of Science, Chiang Mai University, \\ Chiang Mai 50200, Thailand
}

Correspondence should be addressed to Jaroon Jakmunee, scijjkmn@chiangmai.ac.th

Received 31 March 2011; Accepted 26 April 2011

Academic Editor: Jianxiu Du

Copyright (C) 2011 J. Junsomboon and J. Jakmunee. This is an open access article distributed under the Creative Commons Attribution License, which permits unrestricted use, distribution, and reproduction in any medium, provided the original work is properly cited.

\begin{abstract}
A simple flow injection with flame photometric detection has been developed for determination of sodium, potassium, and total alkalies in portland cement, fly ash, admixtures, and water of concrete. A liquid sample or a digest of solid sample was injected into a water carrier stream which flowed to a flame photometer. A change in emission intensity at a selected wavelength was recorded as a peak. An amplifier circuit was fabricated, which helped improve sensitivity of the flame photometer. Calibration graphs in the range of $0.05-1.0 \mathrm{mg} \mathrm{L}^{-1}$ and $1.0-20.0 \mathrm{mg} \mathrm{L}^{-1}$ were obtained with a detection limit of $0.02 \mathrm{mg} \mathrm{L}^{-1}$, for both potassium and sodium determination. Relative standard deviations for 11 replicates of injecting of $10 \mathrm{mg} \mathrm{L}^{-1}$ potassium and sodium solutions were 1.69 and $1.79 \%$, respectively. Sample throughput of $120 \mathrm{~h}^{-1}$ was achieved. The proposed method was successfully applied to portland cement, fly ash, admixtures, and water samples validated by the ASTM standard method and certified reference materials of portland cement.
\end{abstract}

\section{Introduction}

Concrete is the most widely used construction material in the world. It is composed of cement and other cementitious materials such as fly ash and slag cement, aggregates (e.g., gravels, crushed rock, and sand), water, and chemical admixture [1]. Cement acts as binding material. It is mixed with water to produce cement paste that glues the aggregates together. Concrete has a good compressive strength (ca. $200 \mathrm{Kg} \mathrm{cm}^{-2}$ ), as the aggregates efficiently carry the compressive load. However, it is weak in its resistance to tension. Reinforced concrete is made by adding steel bars, steel fibers, glass fibers, or plastic fibers to concrete, in order to improve its tensile strength. Admixtures are materials that are added to give certain characteristics not obtainable with plain concrete mixes. They may help speed up or slow down the hydration of concrete and improve durability of concrete and plasticity or workability of fresh concrete. Since many reactions occur in concrete, some reactions are not desirable, especially the alkali-silica reaction (ASR). ASR is the neutralization reaction between alkaline cement paste and reactive noncrystalline (amorphous) silica, which is found in many common aggregates. This reaction produces swelling gel products which exerts an expansive pressure inside concrete. ASR occurs over time in concrete and can cause serious expansion and cracking of concrete, leading to critical structural problems. ASR can be mitigated by three complementary approaches; that is, limit the alkali metal contents of the cement, limiting the reactive silica content of the aggregate, and neutralizing the excessive alkalinity of cement at the early stage of the cement setting by adding very fine siliceous materials or pozzolanic materials to concrete mixture. Sodium hydroxide and potassium hydroxide are the most reactive alkalies in cement. Many standards set limits 
on the alkali as "equivalent sodium oxide $\left(\mathrm{Na}_{2} \mathrm{O}\right)$ " content of cement and other materials [2-4]. Equivalent sodium oxide is calculated as follows: $\left.\left(\mathrm{Na}_{2} \mathrm{O}\right)_{\mathrm{e}}=\mathrm{Na}_{2} \mathrm{O}+0.658 \mathrm{~K}_{2} \mathrm{O}\right)$. Thus, it is important to determine sodium and potassium in cement and other materials for quality control of the products.

Atomic absorption spectrophotometry (AAS) and flame emission spectrophotometry (FES), or flame photometry have been approved to be standard methods for determination of sodium and potassium in cement and materials for making concrete $[2,3]$. Flow injection analysis (FIA) has been incorporated to these detectors in order to gain various advantages such as fast and convenient operation, on-line sample preparation, and high degrees of automation [5-18]. FAAS and FES are widely used as detection systems because they provide high sensitivity and selectivity. Other detection techniques which involve smaller instruments such as ionselective electrode $[19,20]$ and turbidimetry [21] with FIA, also developed, but their selectivities are rather limited.

In this work, we develop a simple FIA with FES detection for determination of sodium and potassium in materials of concrete. FIA improved performance of FES in terms of increasing sample throughput, helping to keep nubelizer and burner clean, and providing higher degrees of automation. A home-made amplification circuit was also incorporated to the FI-FES system in order to improve sensitivity and detection limit of the FES. The developed system was successfully applied for the analysis of cement, aggregates, and admixtures of concrete, so it would be suitable to be used as the automated analytical system for routine quality control of these materials.

\section{Experimental}

2.1. Chemicals. Analytical reagent grade chemicals were used and deionized water (obtained from a system of Milli-Q, Millipore, Sweden) was used throughout for preparation of solutions. A sodium standard stock solution $\left(1000 \mathrm{mg} \mathrm{L}^{-1}\right)$ was prepared by dissolving $0.2542 \mathrm{~g}$ of sodium chloride (Merck, Darmstadt, Germany) in $0.1 \mathrm{M}$ hydrochloric acid and making up to a volume of $100 \mathrm{~mL}$ in a volumetric flask. A potassium standard stock solution $\left(1000 \mathrm{mg} \mathrm{L}^{-1}\right)$ was prepared by dissolving $0.1907 \mathrm{~g}$ of potassium chloride (Merck, Darmstadt, Germany) in 0.1 M hydrochloric acid and adjusting to the final volume of $100 \mathrm{~mL}$. Working standard solutions of sodium and potassium were prepared daily by appropriately diluting their stock solutions with water. A $0.1 \mathrm{M}$ hydrochloric acid solution was prepared by diluting concentrated hydrochloric acid (Merck, Darmstadt, Germany) with water.

2.2. Instrumentation and Procedure. The FI system used is depicted in Figure 1. It is a simple single line FI setup consisting of a peristaltic pump (Ismatec, Switzerland), a six-port injection valve (Upchurch, USA), a flame emission spectrophotometer (Corning 410, Corning, Halstead, England), a home-made amplification/data acquisition unit, and a personal computer.

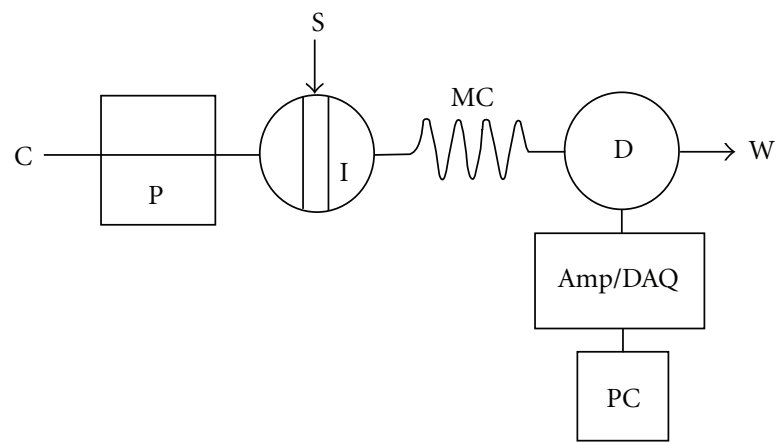

FIGURE 1: FI manifold of flow injection flame photometric system for determination of $\mathrm{Na}$ and $\mathrm{K}$; C = DI water carrier, $\mathrm{S}=$ standard/sample, $\mathrm{P}=$ peristaltic pump, $\mathrm{I}=$ injection valve, $\mathrm{MC}=$ mixing coil, $\mathrm{W}=$ waste, $\mathrm{D}=$ flame photometric detector, Amp/DAQ = data acquisition unit with amplifier (see Figure 2), $\mathrm{PC}=$ personal computer.

Figure 2 illustrates a schematic diagram of the data acquisition unit with an amplifier circuit. Analog signal from the FES instrument was passed to the operational amplifier (Op amp) input. The signal was amplified by the Op amp which was connected as a noninverting amplifier circuit. Amplification gain could be set by adjusting selector switch (SW) to select a suitable amplification resistor $\left(\mathrm{R}_{2}\right)$. Amplification gain is defined as $1+R_{2} / R_{1}$. The amplified signal was then passed to an analog to digital converter circuit (ADC) consisting of a 12 bit ADC integrated circuit, LTC1298, in order to convert the analog signal to digital signal which was suitable for recording by a computer. The data acquisition was performed by a Basic Stamp 2SX microcontroller, employing a software program written inhouse in Visual Basic 6.0. The recorded data was imported to eDAQ chart software (eDAQ, Australia) for further evaluation for peak heights of the FIA peaks.

Using the FI system as shown in Figure 1, standard or sample solution was injected into a carrier stream and flowed to the FES burner. Output signal from the FES was amplified and continuously recorded on a personal computer as FIA peak. Peak height obtained was directly proportional to concentration of the analyte and could be used for construction of a calibration graph for determination of sodium or potassium in sample.

2.3. Sample Preparation. Cement and fly ash samples were prepared according to the standard method, ASTM C11409 [2]. The sample was accurately weighed to $1.0000 \mathrm{~g}$ and put into a $150 \mathrm{~mL}$ beaker. Then $20 \mathrm{~mL}$ of water and $5 \mathrm{~mL}$ of concentrated hydrochloric acid were consecutively added, followed by adding water to the mark of $50 \mathrm{~mL}$. The suspension was digested on a hot plate for about $15 \mathrm{~min}$ and the solution was filtered through a Whatman No. 40 filter paper into a $100 \mathrm{~mL}$ volumetric flask. Finally, water was added to the mark to obtain a solution ready for analysis.

Sample of liquid admixture of concrete was prepared by using the standard method, BS EN 480-12: 1998 [3]. Briefly, sample was weighed accurately to $1.0000 \mathrm{~g}$, put in 
TABLE 1: Recoveries of sodium and potassium determined by FI-FES.

\begin{tabular}{|c|c|c|c|c|c|c|}
\hline \multirow{2}{*}{ Sample } & \multicolumn{3}{|c|}{$\mathrm{Na}$ concentration found $\left(\mathrm{mg} \mathrm{L}^{-1}\right)$} & \multicolumn{3}{|c|}{ K concentration found $\left(\mathrm{mg} \mathrm{L}^{-1}\right)$} \\
\hline & $\begin{array}{l}\text { Original } \\
\text { sample }\end{array}$ & $\begin{array}{c}\text { With } \\
5 \mathrm{mg} \mathrm{L}^{-1} \mathrm{Na} \\
\text { added }\end{array}$ & $\%$ Recovery & $\begin{array}{l}\text { Original } \\
\text { sample }\end{array}$ & $\begin{array}{c}\text { With } 5 \mathrm{mg} \mathrm{L}^{-1} \mathrm{~K} \\
\text { added }\end{array}$ & \% Recovery \\
\hline Cement & $9.76 \pm 0.04$ & $14.35 \pm 0.01$ & 91.8 & $12.37 \pm 0.25$ & $16.66 \pm 0.09$ & 85.8 \\
\hline Fly ash & $4.32 \pm 0.05$ & $8.80 \pm 0.02$ & 89.6 & $4.98 \pm 0.07$ & $9.31 \pm 0.17$ & 86.6 \\
\hline Admixture 1 & $8.77 \pm 0.01$ & $13.86 \pm 0.18$ & 101.8 & $0.00 \pm 0.00$ & $5.31 \pm 0.08$ & 106.2 \\
\hline Admixture 2 & $6.19 \pm 0.11$ & $10.65 \pm 0.05$ & 89.2 & $1.87 \pm 0.18$ & $6.59 \pm 0.15$ & 94.4 \\
\hline
\end{tabular}

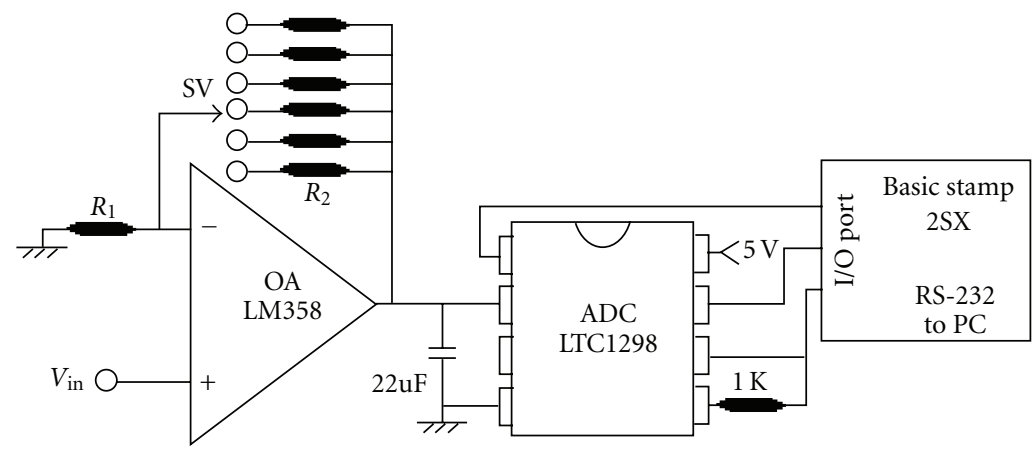

FIGURE 2: Schematic diagram of an amplification and data acquisition unit. Resistor $\mathrm{R}_{1}=2 \mathrm{~K}, \mathrm{R}_{2}=0-1000 \mathrm{~K}$, amplification gain $=1+\mathrm{R}_{2} / \mathrm{R}_{1}$.

TABLE 2: Analyses of certified reference materials of portland cement by FI-FES.

\begin{tabular}{lcccc}
\hline \multirow{2}{*}{ Sample } & \multicolumn{2}{c}{$\% \mathrm{Na}_{2} \mathrm{O}$} & \multicolumn{2}{c}{$\% \mathrm{~K}_{2} \mathrm{O}$} \\
& FI-FES & $\begin{array}{c}\text { Certified } \\
\text { value }\end{array}$ & FI-FES & $\begin{array}{c}\text { Certified } \\
\text { value }\end{array}$ \\
\hline CRM 1889 & $0.134 \pm 0.001$ & 0.11 & $0.264 \pm 0.002$ & 0.32 \\
CRM 633 & $0.661 \pm 0.002$ & 0.64 & $0.149 \pm 0.003$ & 0.16 \\
CRM 638 & $0.151 \pm 0.001$ & 0.12 & $0.572 \pm 0.002$ & 0.59 \\
\hline
\end{tabular}

a $150 \mathrm{~mL}$ beaker, added to $20 \mathrm{~mL}$ of water and $1 \mathrm{~mL}$ of $(1: 1)$ concentrated nitric acid. The solution was adjusted to $100 \mathrm{~mL}$ with water in a volumetric flask.

Sample of water for making concrete (ground water and tab water) was prepared according to the standard method, AWWA: 1998 [22]. The sample was filtered through a Whatman No. 42 filter paper, and then $50 \mathrm{~mL}$ of sample was pipetted into a $150 \mathrm{~mL}$ beaker, added to $5 \mathrm{~mL}$ of conc. nitric acid, and digested on a hot plate to nearly dryness. The digested solution was filtered through a Whatman No. 42 filter paper into a $100 \mathrm{~mL}$ volumetric flask and adjusted to the mark with water.

\section{Results and Discussion}

3.1. Optimization of the FI-FES for Determination of Sodium. FI-FES system as shown in Figure 1 was used with the preliminary conditions as follows: flow rate of the carrier stream of $2.0 \mathrm{~mL} \mathrm{~min}^{-1}$, sample volume of $200 \mu \mathrm{L}$, and no mixing coil connected between an injection valve and a detector. An

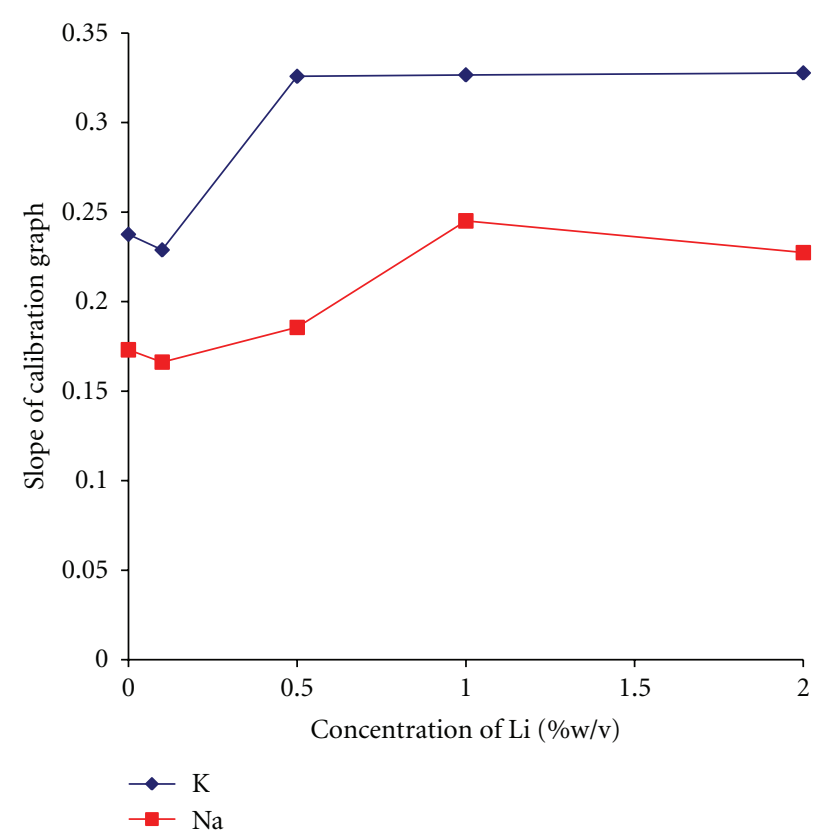

FIGURE 3: Effect of Li added to carrier solution on sensitivity of sodium and potassium determination by FI-FES.

amplifier gain was optimized for determination of sodium in concentration range of $1-20 \mathrm{mg} \mathrm{L}^{-1}$ which is the normal analytical range used in routine analysis. The amplifier gain of $30 \times$ was selected as it gave an analog signal of the $20 \mathrm{mg} \mathrm{L}^{-1} \mathrm{Na}$ close to $5 \mathrm{~V}$ which is the maximum allowable input signal of the ADC circuit. 
TABLE 3: Contents of sodium, potassium, and total alkalies determined by FI-FES and batchwise FES methods.

\begin{tabular}{|c|c|c|c|c|c|c|}
\hline \multirow{2}{*}{ Sample } & \multicolumn{2}{|c|}{$\% \mathrm{Na}_{2} \mathrm{O}$} & \multicolumn{2}{|c|}{$\% \mathrm{~K}_{2} \mathrm{O}$} & \multicolumn{2}{|c|}{$\%$ Total alkalies } \\
\hline & FI-FES & FES & FI-FES & FES & FI-FES & FES \\
\hline \multicolumn{7}{|l|}{ Cement } \\
\hline 1 & $0.124 \pm 0.001$ & $0.121 \pm 0.001$ & $0.299 \pm 0.002$ & $0.292 \pm 0.001$ & 0.321 & 0.313 \\
\hline 2 & $0.267 \pm 0.002$ & $0.262 \pm 0.001$ & $0.332 \pm 0.004$ & $0.322 \pm 0.002$ & 0.485 & 0.474 \\
\hline 3 & $0.122 \pm 0.001$ & $0.117 \pm 0.001$ & $0.268 \pm 0.002$ & $0.265 \pm 0.001$ & 0.299 & 0.291 \\
\hline 4 & $0.052 \pm 0.001$ & $0.047 \pm 0.001$ & $0.053 \pm 0.001$ & $0.045 \pm 0.001$ & 0.087 & 0.076 \\
\hline 5 & $0.437 \pm 0.002$ & $0.435 \pm 0.002$ & $0.600 \pm 0.007$ & $0.637 \pm 0.003$ & 0.831 & 0.855 \\
\hline 6 & $0.076 \pm 0.001$ & $0.070 \pm 0.001$ & $0.131 \pm 0.002$ & $0.128 \pm 0.001$ & 0.162 & 0.155 \\
\hline 7 & $0.108 \pm 0.001$ & $0.107 \pm 0.001$ & $0.277 \pm 0.002$ & $0.273 \pm 0.001$ & 0.291 & 0.286 \\
\hline 8 & $0.139 \pm 0.001$ & $0.134 \pm 0.001$ & $0.294 \pm 0.004$ & $0.290 \pm 0.001$ & 0.333 & 0.325 \\
\hline 9 & $0.098 \pm 0.002$ & $0.091 \pm 0.001$ & $0.249 \pm 0.003$ & $0.247 \pm 0.001$ & 0.262 & 0.254 \\
\hline 10 & $0.118 \pm 0.001$ & $0.113 \pm 0.001$ & $0.326 \pm 0.005$ & $0.326 \pm 0.001$ & 0.333 & 0.327 \\
\hline \multicolumn{7}{|l|}{ Fly ash } \\
\hline 11 & $0.079 \pm 0.002$ & $0.074 \pm 0.001$ & $0.039 \pm 0.001$ & $0.035 \pm 0.001$ & 0.104 & 0.098 \\
\hline 12 & $0.026 \pm 0.001$ & $0.023 \pm 0.001$ & $0.035 \pm 0.001$ & $0.033 \pm 0.001$ & 0.049 & 0.045 \\
\hline 13 & $1.608 \pm 0.035$ & $1.595 \pm 0.008$ & $1.339 \pm 0.016$ & $1.455 \pm 0.007$ & 2.489 & 2.553 \\
\hline 14 & $0.547 \pm 0.006$ & $0.574 \pm 0.013$ & $0.571 \pm 0.013$ & $0.627 \pm 0.001$ & 0.922 & 0.986 \\
\hline 15 & $0.155 \pm 0.004$ & $0.147 \pm 0.001$ & $0.172 \pm 0.002$ & $0.167 \pm 0.001$ & 0.268 & 0.257 \\
\hline 16 & $1.664 \pm 0.037$ & $1.658 \pm 0.008$ & $1.407 \pm 0.012$ & $1.552 \pm 0.007$ & 2.590 & 2.680 \\
\hline 17 & $1.989 \pm 0.016$ & $1.983 \pm 0.008$ & $1.543 \pm 0.017$ & $1.664 \pm 0.007$ & 3.005 & 3.077 \\
\hline 18 & $0.098 \pm 0.001$ & $0.093 \pm 0.001$ & $0.177 \pm 0.003$ & $0.174 \pm 0.001$ & 0.214 & 0.207 \\
\hline 19 & $1.771 \pm 0.034$ & $1.763 \pm 0.008$ & $1.490 \pm 0.005$ & $1.639 \pm 0.007$ & 2.751 & 2.841 \\
\hline 20 & $1.839 \pm 0.023$ & $1.837 \pm 0.015$ & $1.333 \pm 0.006$ & $1.461 \pm 0.012$ & 2.715 & 2.798 \\
\hline \multicolumn{7}{|c|}{ Admixture } \\
\hline 21 & $0.159 \pm 0.001$ & $0.162 \pm 0.001$ & $0.014 \pm 0.001$ & $0.012 \pm 0.001$ & 0.168 & 0.171 \\
\hline 22 & $0.158 \pm 0.003$ & $0.159 \pm 0.001$ & $0.008 \pm 0.001$ & $0.005 \pm 0.001$ & 0.164 & 0.162 \\
\hline 23 & $0.153 \pm 0.005$ & $0.150 \pm 0.003$ & $0.020 \pm 0.001$ & $0.017 \pm 0.001$ & 0.166 & 0.161 \\
\hline 24 & $4.584 \pm 0.099$ & $4.555 \pm 0.014$ & $0.014 \pm 0.001$ & $0.011 \pm 0.001$ & 4.593 & 4.562 \\
\hline 25 & $2.182 \pm 0.026$ & $2.165 \pm 0.008$ & $0.186 \pm 0.001$ & $0.199 \pm 0.001$ & 2.305 & 2.296 \\
\hline 26 & $0.157 \pm 0.005$ & $0.153 \pm 0.003$ & $0.017 \pm 0.001$ & $0.015 \pm 0.001$ & 0.168 & 0.163 \\
\hline 27 & $0.195 \pm 0.001$ & $0.186 \pm 0.001$ & $0.016 \pm 0.001$ & $0.013 \pm 0.001$ & 0.206 & 0.195 \\
\hline 28 & $0.161 \pm 0.001$ & $0.157 \pm 0.001$ & $0.012 \pm 0.001$ & $0.010 \pm 0.001$ & 0.169 & 0.164 \\
\hline 29 & $0.170 \pm 0.006$ & $0.167 \pm 0.001$ & $0.009 \pm 0.001$ & $0.005 \pm 0.001$ & 0.175 & 0.170 \\
\hline 30 & $0.178 \pm 0.005$ & $0.168 \pm 0.001$ & $0.022 \pm 0.001$ & $0.022 \pm 0.001$ & 0.192 & 0.183 \\
\hline \multicolumn{7}{|l|}{ Water } \\
\hline 31 & $0.203 \pm 0.004$ & $0.197 \pm 0.001$ & $0.043 \pm 0.001$ & $0.043 \pm 0.001$ & 0.232 & 0.225 \\
\hline 32 & $0.196 \pm 0.004$ & $0.194 \pm 0.001$ & $0.043 \pm 0.001$ & $0.043 \pm 0.001$ & 0.224 & 0.223 \\
\hline 33 & $0.190 \pm 0.001$ & $0.186 \pm 0.001$ & $0.044 \pm 0.001$ & $0.045 \pm 0.001$ & 0.219 & 0.216 \\
\hline 34 & $0.235 \pm 0.005$ & $0.234 \pm 0.001$ & $0.048 \pm 0.001$ & $0.050 \pm 0.001$ & 0.267 & 0.267 \\
\hline 35 & $0.239 \pm 0.005$ & $0.227 \pm 0.001$ & $0.051 \pm 0.002$ & $0.053 \pm 0.001$ & 0.272 & 0.261 \\
\hline
\end{tabular}

Effect of flow rate of the carrier stream was investigated by injecting a series of sodium standard solution (1$20 \mathrm{mg} \mathrm{L}^{-1}$ ) into the system and a calibration graph was constructed by plotting peak height obtained versus sodium concentration for each flow rate used. Calibration equations, $y=0.181 x-0.037, r^{2}=0.9994, y=0.181 x+0.095, r^{2}=$ 0.9975 and $y=0.218 x+0.078, r^{2}=0.9955$ were obtained for flow rate of 1.0, 2.0, and $3.0 \mathrm{~mL} \mathrm{~min}^{-1}$, respectively. Flow rate of $3.0 \mathrm{~mL} \mathrm{~min}^{-1}$ was chosen since it provided adequate sensitivity and high sample throughput $\left(120 \mathrm{~h}^{-1}\right)$. Flow rate of higher than $3.0 \mathrm{~mL} \mathrm{~min}^{-1}$ was not investigated in order to avoid high consumption of the carrier.

Effect of mixing coil length was then studied in the range of $0-100 \mathrm{~cm}$. Calibration equations, $y=0.217 x+0.078, r^{2}=$ 0.9956, $y=0.182 x+0.056, r^{2}=0.9993, y=0.155 x+0.014$, $r^{2}=0.9998$ and $y=0.133 x+0.025, r^{2}=0.9996$ were obtained for mixing coil lengths of $0,25,50$, and $100 \mathrm{~cm}$, respectively. The longer the coil length the smaller the slope 


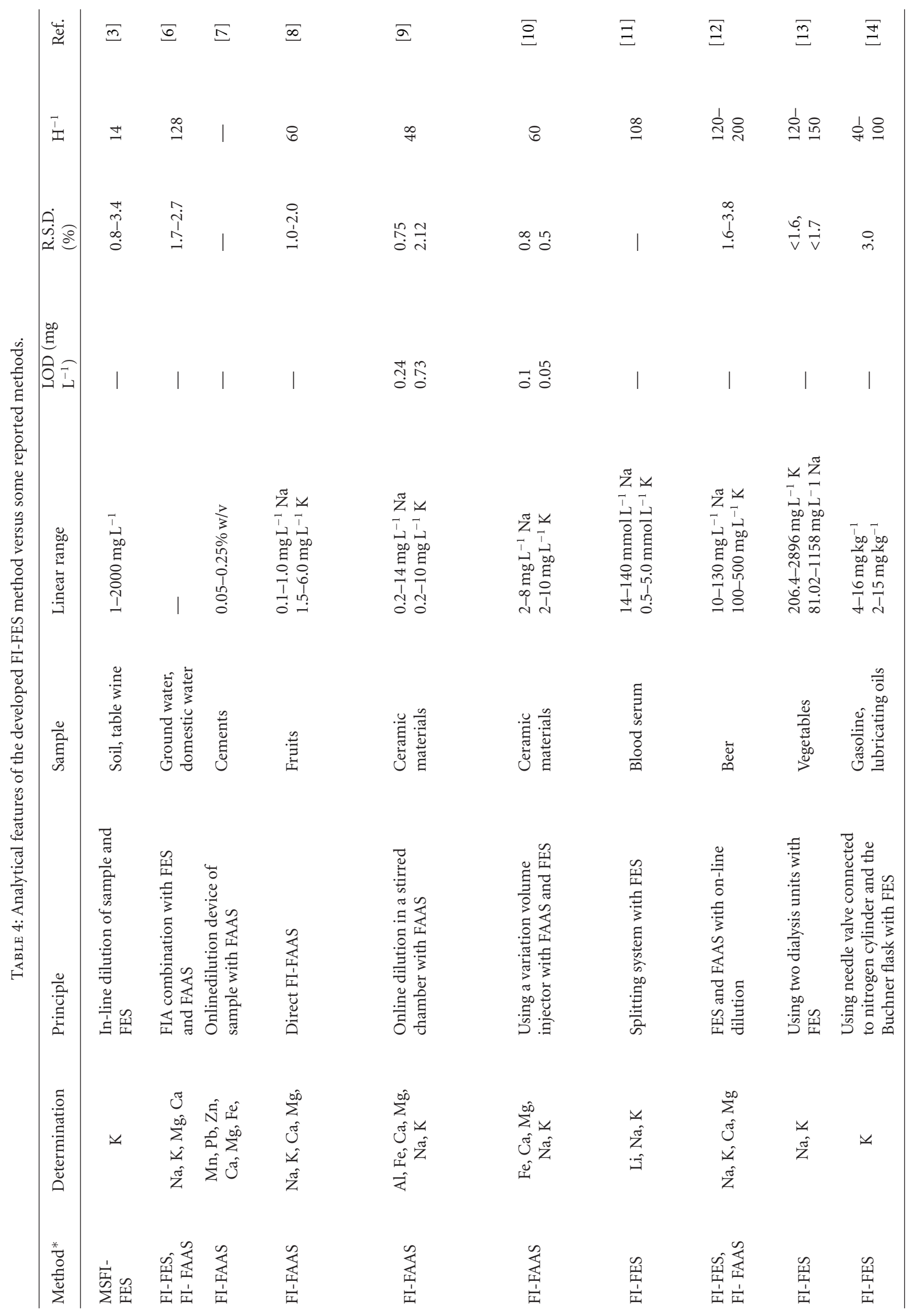




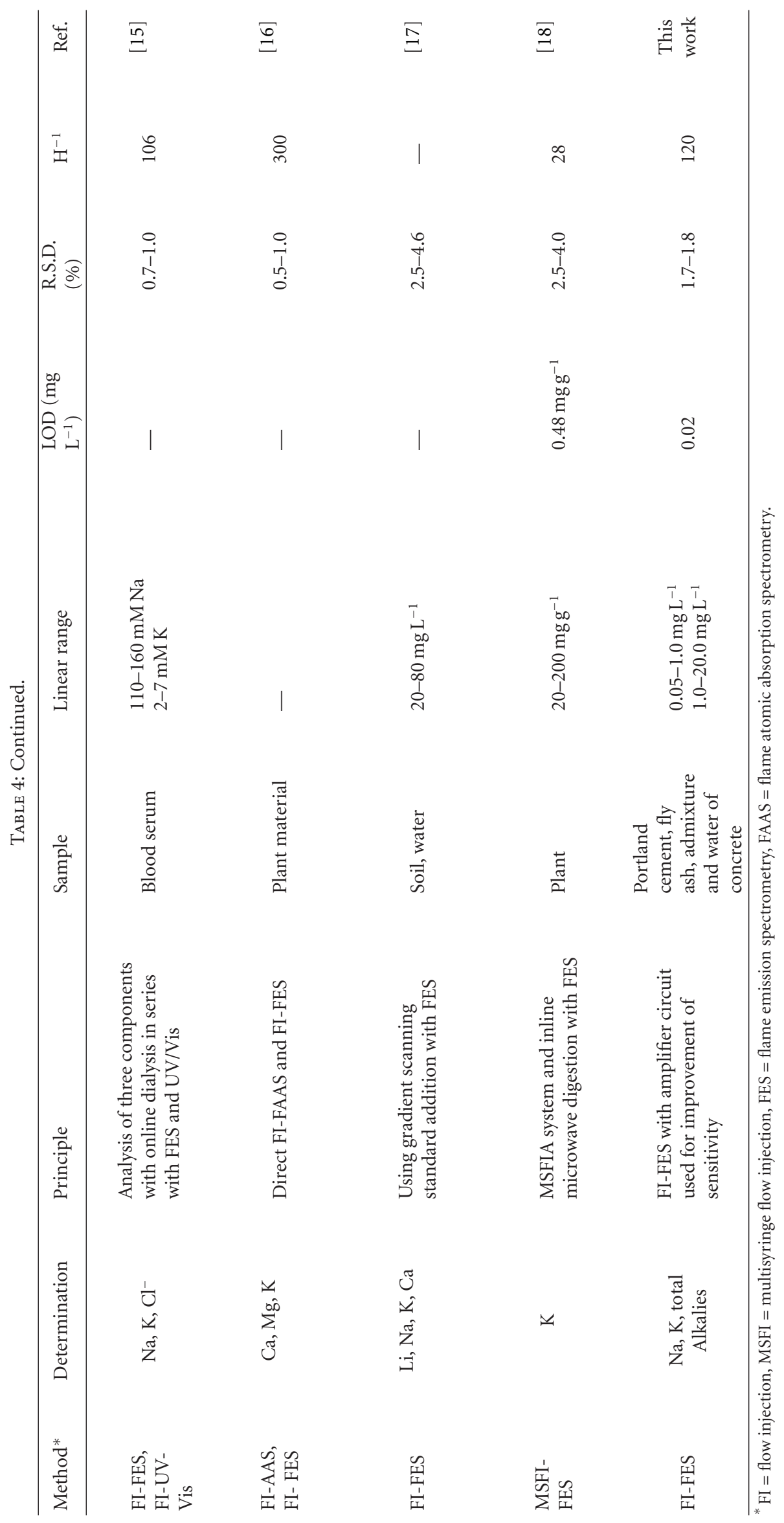




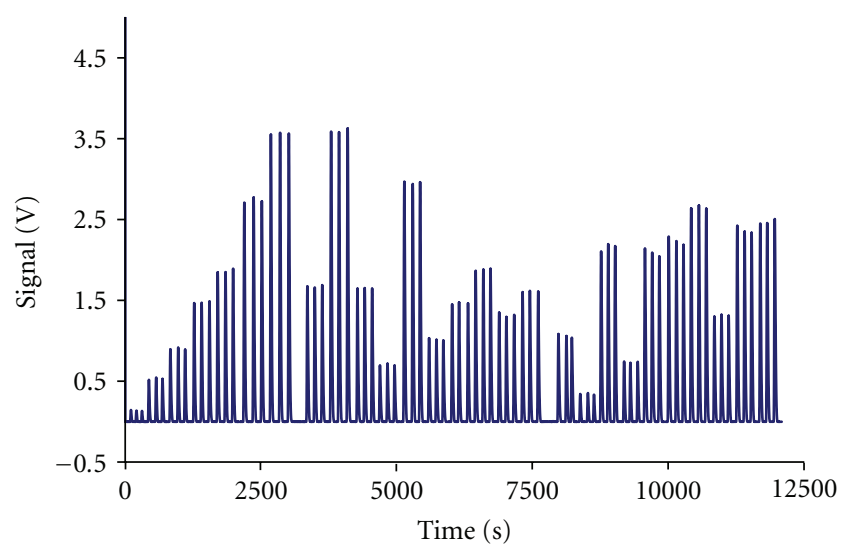

FIGURE 4: FIA grams of sodium standard solutions and some samples. From left to right standard solution 1.0, 3.0, 5.0, 8.0, $10.0,15.0$, and $20.0 \mathrm{mg} \mathrm{L}^{-1} \mathrm{Na}$ and sample's number 1-20, triplicate injections for each solution.

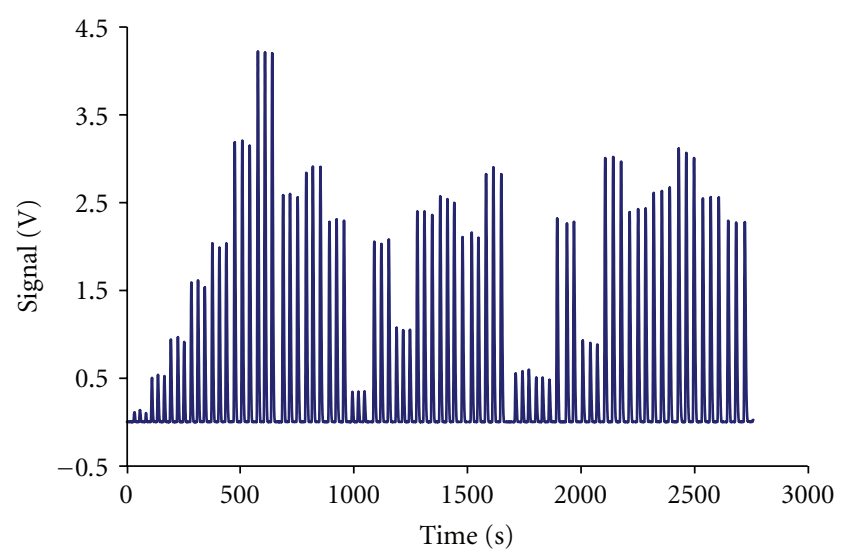

Figure 5: FIA grams of potassium standard solutions and some samples. From left to right standard solution 1.0, 3.0, 5.0, 8.0, $10.0,15.0$, and $20.0 \mathrm{mg} \mathrm{L}^{-1} \mathrm{~K}$ and sample's number $1-20$, triplicate injections for each solution.

and observed due to the higher dispersion of the injected solution, so the system without mixing coil was selected for further experiments.

Effect of sample volume in the range of $75-200 \mu \mathrm{L}$ was investigated. It was found that the higher the sample volume the higher sensitivity was obtained, that is, calibration equations, $y=0.142 x+0.037, r^{2}=0.9988, y=0.177 x+$ $0.044, r^{2}=0.9992$ and $y=0.218 x+0.077, r^{2}=0.9955$ for sample volumes of 75,100 , and $200 \mu \mathrm{L}$, respectively, were obtained. Sample volume of $100 \mu \mathrm{L}$ was chosen as it provided enough sensitivity for the analysis of sample.

3.2. Optimization of FI-FES for Determination of Potassium. Employing FI-FES system as shown in Figure 1 and the following preliminary conditions: carrier flow rate of $2.0 \mathrm{~mL} \mathrm{~min}^{-1}$, sample volume of $200 \mu \mathrm{L}$, and no mixing coil, an amplifier gain was optimized for the determination of potassium in the concentration range of $1-20 \mathrm{mg} \mathrm{L}^{-1}$. The amplifier gain of $50 \times$ was selected as it gave an analog signal of $20 \mathrm{mg} \mathrm{L}^{-1} \mathrm{~K}$ close to $5 \mathrm{~V}$ which is the maximum allowable input signal of the ADC circuit.

Effect of flow rate of carrier stream was studied similar to Section 3.1. Calibration equations for the injection of potassium standard solutions in the range of $1-20 \mathrm{mg} \mathrm{L}^{-1}$ with carrier flow rates of $1.0,2.0$, and $3.0 \mathrm{~mL} \mathrm{~min}^{-1}$ were $y=0.215 x-0.032, r^{2}=0.9991, y=0.238 x-0.001$, $r^{2}=0.9994$ and $y=0.244 x+0.113, r^{2}=0.9892$, respectively. Flow rate of $2.0 \mathrm{~mL} \mathrm{~min}^{-1}$ was chosen because it provided good sensitivity and linearity.

The studied mixing coil lengths of $0,25,50$, and $100 \mathrm{~cm}$ provided calibration equations of $y=0.220 x-0.051, r^{2}=$ 0.9987, $y=0.196 x-0.067, r^{2}=0.9990$ and $y=0.178 x-$ $0.051, r^{2}=0.9976$, respectively. The FI system without mixing coil was selected for further studies since it gave high sensitivity.

Effect of sample volume was investigated. Calibration equations of $y=0.185 x-0.067, r^{2}=0.9984, y=0.222 x-$ $0.053, r^{2}=0.9996$ and $y=0.2378 x-0.001, r^{2}=0.9994$ were obtained for sample volumes of 75,100 , and $200 \mu \mathrm{L}$, respectively. Sample volume of $100 \mu \mathrm{L}$ was selected as it provided higher sensitivity and narrower peak.

By adding lithium into a carrier solution to reduce ionization of sodium and potassium, the sensitivity could be slightly enhanced as shown in Figure 3. However, at 2.0\% $(w / v) ~ L i$ the fluctuation of baseline was observed. Thus, water carrier without ionization-suppression buffer was chosen since it used no chemical and helped to keep the nebulizer and burner of FES instrument clean.

3.3. Analytical Characteristics. Under the selected conditions, flow rate of water carrier of $3.0 \mathrm{~mL} \mathrm{~min}^{-1}$, sample volume of $100 \mu \mathrm{L}$, and no mixing coil, two linear calibration ranges for determination of sodium were attained, that is, $y=$ $0.284 x+0.004, r^{2}=0.9970$ for $0.05-1.0 \mathrm{mg} \mathrm{L}^{-1} \mathrm{Na}$ (with amplifier gain 50x) and $y=0.181 x+0.001, r^{2}=0.9989$ for $1.0-20.0 \mathrm{mg} \mathrm{L}^{-1} \mathrm{Na}$ (with amplifier gain $30 \times$ ). FIA grams of the standard solutions of sodium and some samples are depicted in Figure 4.

Two linear calibration graphs were also obtained for the determination of potassium, that is, $y=1.931 x+$ $0.1138, r^{2}=0.9966$ for $0.05-1.0 \mathrm{mg} \mathrm{L}^{-1} \mathrm{~K}$ (with amplifier gain 500x) and $y=0.218 x-0.134, r^{2}=0.9996$ for $1.0-20.0 \mathrm{mg} \mathrm{L}^{-1} \mathrm{~K}$ (with amplifier gain $50 \times$ ). Figure 5 illustrates FIA grams of potassium standard solutions and some samples.

Detection limits (3 times the standard deviation of the blank/slope of analytical curve) of $0.02 \mathrm{mg} \mathrm{L}^{-1}$ were achieved for both sodium and potassium determinations. Relative standard deviations for 11 replicates of injection of $10 \mathrm{mg} \mathrm{L}^{-1}$ of sodium and potassium were 1.79 and 1.69 , respectively. Sample throughput of $120 \mathrm{~h}^{-1}$ was obtained.

3.4. Validation of the Method. Recovery study was performed by spiking standard solution of sodium or potassium into the prepared solutions of cement, fly ash, and concrete admixture solutions. Recoveries were obtained in the ranges 
of $89-102 \%$ and $86-106 \%$ for sodium and potassium, respectively (Table 1 ).

Certified reference materials of portland cements were analyzed by the proposed method. The results are summarized in Table 2. The contents of $\mathrm{Na}_{2} \mathrm{O}$ and $\mathrm{K}_{2} \mathrm{O}$ as determined by the proposed FI-FES method were in acceptable range of the certified values, indicating that the method could be applied for these samples.

3.5. Application to Real Samples. The developed method was applied to cement, fly ash, admixture solutions, and water for making concrete. The samples were prepared as described in Section 2.3 before injecting the obtained solution into the FI system. Thirty-five samples were analyzed, and the contents of sodium and potassium, reported as $\% \mathrm{Na}_{2} \mathrm{O}$ and $\% \mathrm{~K}_{2} \mathrm{O}$ are summarized in Table 3.

The routinely used batchwise FES method [2-4] was also employed for analyses of all samples for comparison. It was found that the results obtained from both methods were not significantly different, as evaluated by $t$-test at $95 \%$ confidence level [23], $t_{\text {calc. }}=0.022$ versus $t_{\text {table }}=$ 2.000 for sodium and $t_{\text {calc. }}=0.166$ versus $t_{\text {table }}=2.000$ for potassium. Correlation plots of the results from both methods gave linear equations, $y=0.995 x-0.177, r^{2}=$ 0.9999 for sodium and $y=1.097 x-1.032, r^{2}=0.9994$ for potassium, respectively. However, the developed FI-FES method was faster and more convenient to perform than the standard method. Analytical signal was recorded and could be retrieved for further evaluation at a later time.

Total alkali contents reported as equivalent sodium oxide are also summarized in Table 3. It was found that total alkali contents found in most samples of cement, admixture, and water were lower than the permissible value of the Thai Industrial Standard which is set to be not higher than $0.6 \%$ [4]. Several samples of fly ash contained total alkalies at level higher than the permissible value.

3.6. Comparison to Other Methods. Analytical features of the developed method were compared to some reported methods as shown in Table 4. The proposed FI-FES system has high sensitivity and provides low limit of detection. It has comparable precision and sample throughput to most of the reported methods. This work is the first report on the application of FI-FES for determination of potassium, sodium, and total alkalies in cement and other materials for making concrete.

\section{Conclusion}

FI-FES method was developed and successfully applied for determination of sodium and potassium in cement and materials of concrete. Amplifier circuit and data acquisition unit were incorporated to the system for improving sensitivity and continuous recording of signal from the FES instrument. FI acts as a sample introduction system for FES and also provides various advantages such as that it is fast and convenient analysis, the small volume of sample $(100 \mu \mathrm{L})$ used in FI helps improve the cleanliness of the nebulizer and burner of the FES, and the system has higher degrees of automation. With further incorporation of an autosampler, the system should be more appropriate for routine analysis.

\section{Acknowledgments}

The Thailand Research Fund (TRF), The Commission on Higher Education (CHE), The Center for Innovation in Chemistry: Postgraduate Education and Research Program in Chemistry (PERCH-CIC), and Physics and Engineering program, Department of Science Service (DSS) are acknowledged for financial supports. The authors thank Edgar Paski for useful discussion.

\section{References}

[1] http://en.wikipedia.org/wiki/Concrete.

[2] ASTM International standard, "Standard test methods for chemical analysis of hydraulic cement (ASTM C114-09)," West Conshohocken, Pa, USA, 2009.

[3] British standard, "Determination of the alkali content of admixtures ( BS EN 480-12 : 1998)," Bristol, UK, 1998.

[4] Thai Industrial standard, "Standard for portland cement part 1 specification (TIS 15 part 1-2547(2004))," Bangkok, Thailand, 2004.

[5] M. I. G. S. Almeida, M. A. Segundo, J. L. F. C. Lima, and A. O. S. S. Rangel, "Interfacing multisyringe flow injection analysis to flame atomic emission spectrometry: an intelligent system for automatic sample dilution and determination of potassium," Journal of Analytical Atomic Spectrometry, vol. 24, no. 3, pp. 340-346, 2009.

[6] W. D. Basson and J. F. Van Staden, "Simultaneous determination of sodium, potassium, magnesium and calcium in surface, ground and domestic water by flow-injection analysis," Fresenius' Zeitschrift fuer Analytische Chemie Labor und Betriebsverfahren, vol. 302, no. 5, pp. 370-374, 1980.

[7] M. A. Bautista, C. P. Sirvent, I. L. García, and M. H. Córdoba, "Flow injection flame atomic absorption spectrometry for slurry atomization: determination of manganese, lead, zinc, calcium, magnesium, iron, sodium and potassium in cements," Fresenius' Journal of Analytical Chemistry, vol. 350, no. 6, pp. 359-364, 1994.

[8] J. L. Burguera, M. Burguera, and G. Becerra, "Simplified flow injection slurry method for direct flame atomic absorption spectometric determination of calcium, magnesium, sodium and potassium in fruits," Water, Air, and Soil Pollution, vol. 5758, pp. 489-493, 1991.

[9] V. Carbonell, A. Sanz, A. Salvador, and M. de la Guardia, "Flow injection flame atomic spectrometric determination of aluminium, iron, calcium, magnesium, sodium and potassium in ceramic material by on-line dilution in a stirred chamber," Journal of Analytical Atomic Spectrometry, vol. 6, no. 3, pp. 233-238, 1991.

[10] M. de La Guardia, A. Morales-Rubio, V. Carbonall, A. Salvador, J. L. Burguera, and M. Burguera, "Flow injection flame atomic spectrometric determination of iron, cacium, magnesium, sodium and potassium in ceramic materials by using a variable-volume injector," Fresenius' Journal of Analytical Chemistry, vol. 345, no. 9-8, pp. 579-584, 1993.

[11] G. N. Doku and V. P. Y. Gadzekpo, "Simultaneous determination of lithium, sodium and potassium in blood serum by 
flame photometric flow-injection analysis," Talanta, vol. 43, no. 5, pp. 735-739, 1996.

[12] S. M. V. Fernandes, A. O. S. S. Rangel, and J. L. F. C. Lima, "Flow injection determination of sodium, potassium, calcium, and magnesium in beer by flame emission and atomic absorption spectrometry," Journal of Agricultural and Food Chemistry, vol. 45, no. 4, pp. 1269-1272, 1997.

[13] J. L. F. C. Lima, A. O. S. S. Rangel, and M. R. S. Souto, "Simultaneous determination of potassium and sodium in vegetables by flame emission spectrometry using a flowinjection system with two dialysis units," Analytical Sciences, vol. 12, no. 1, pp. 81-85, 1996.

[14] G. E. Roscoe, R. Miles, and C. G. Taylor, "Determination of potassium in gasoline and lubricating oils by a flowinjection technique with flame atomic emission spectrometric detection," Analytica Chimica Acta, vol. 234, no. 2, pp. 439444, 1990.

[15] J. F. V. van Staden, "Simultaneous flow-injection analysis of three components with on-line dialyzers in series. Determination of sodium, potassium and chloride in blood serum," Talanta, vol. 38, no. 9, pp. 1033-1039, 1991.

[16] E. A. G. Zagatto, F. J. Krug, H. Bergamin F, S. S. Jørgensen, and B. F. Reis, "Merging zones in flow injection analysis. Part 2. Determination of calcium, magnesium and potassium in plant material by continuous flow injection atomic absorption and flame emission spectrometry," Analytica Chimica Acta, vol. 104, no. 2, pp. 279-284, 1979.

[17] F. Zhaolun, J. M. Harris, J. Ruzicka, and E. H. Hansen, "Simultaneous flame photometric determination of lithium, sodium, potassium, and calcium by flow injection analysis with gradient scanning standard addition," Analytical Chemistry, vol. 57, no. 7, pp. 1457-1461, 1985.

[18] M. I. G. S. Almeida, M. A. Segundo, J. L. F. C. Lima, and A. O. S. S. Rangel, "Direct introduction of slurry samples in multisyringe flow injection analysis: determination of potassium in plant samples," Analytical Sciences, vol. 24, no. 5, pp. 601-606, 2008.

[19] M. I. G. S. Almeida, M. A. Segundo, J. L. F. C. Lima, and A. O. S. S. Rangel, "Potentiometric multi-syringe flow injection system for determination of exchangeable potassium in soils with in-line extraction," Microchemical Journal, vol. 83, no. 2, pp. 75-80, 2006.

[20] S. Komaba, J. Arakawa, M. Seyama, T. Osaka, I. Satoh, and S. Nakamura, "Flow injection analysis of potassium using an all-solid-state potassium-selective electrode as a detector," Talanta, vol. 46, no. 6, pp. 1293-1297, 1998.

[21] J. L. F. C. Lima, A. O. S. S. Rangel, M. R. S. Souto, and E. A. G. Zagatto, "Turbidimetric flow-injection determination of total nitrogen and potassium in vegetables," Analytica Chimica Acta, vol. 356, no. 2-3, pp. 259-265, 1997.

[22] American Water Works Association (AWWA), Standard Methods for The Examination of Water and Wastewater, American Public Health Association, Northwest, Wash, USA, 20th edition, 1998.

[23] G. D. Christian, Analytical Chemistry, Wiley, NY, USA, 6th edition, 2004. 


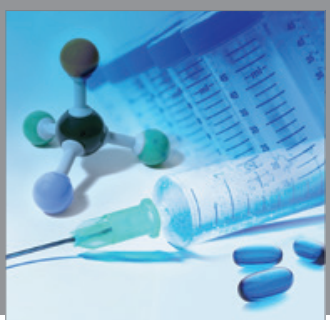

International Journal of

Medicinal Chemistry

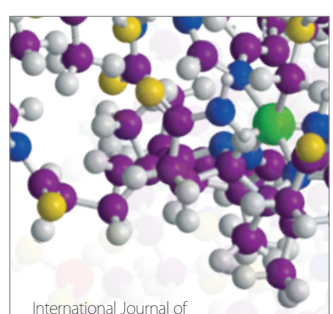

Carbohydrate Chemistry

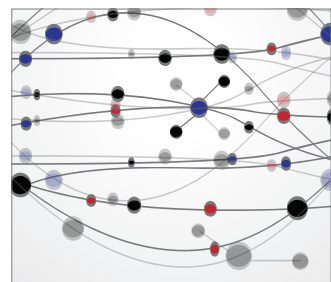

The Scientific World Journal
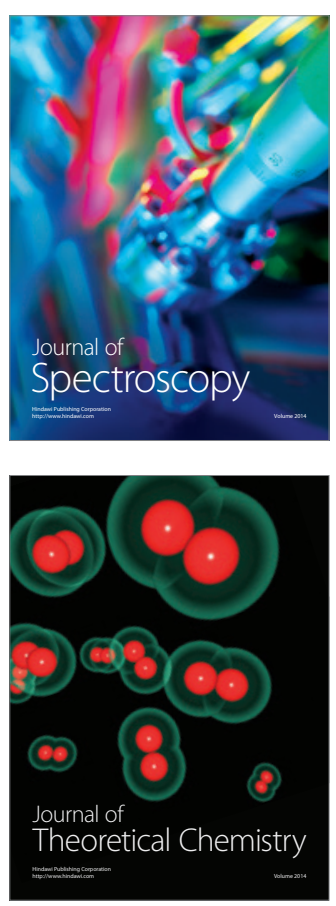
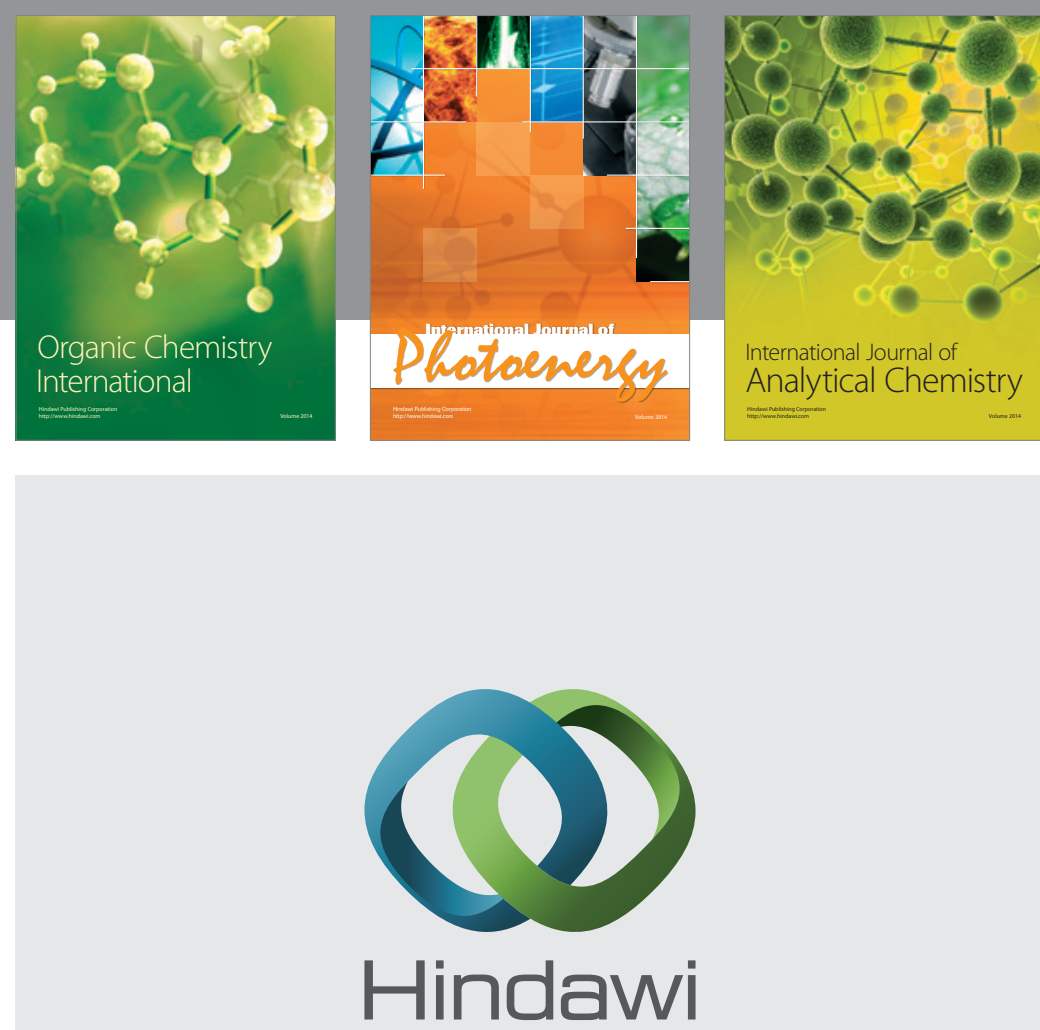

Submit your manuscripts at

http://www.hindawi.com
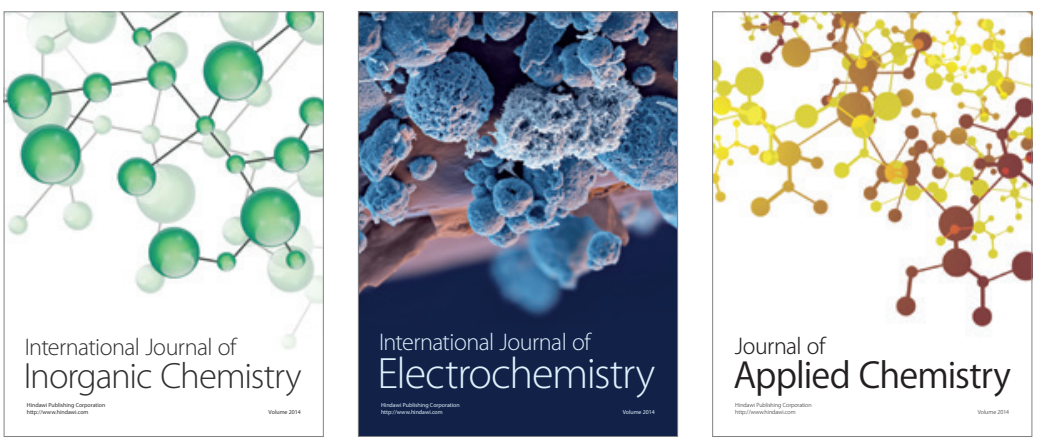

Journal of

Applied Chemistry
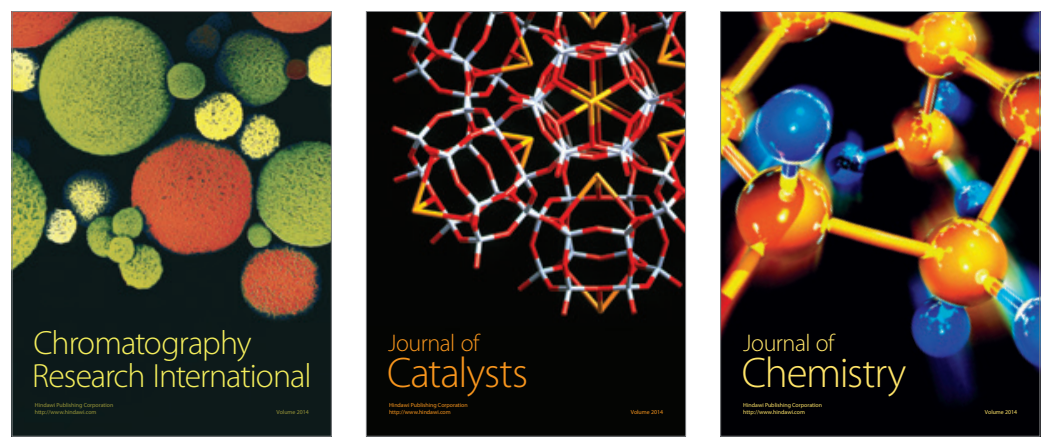
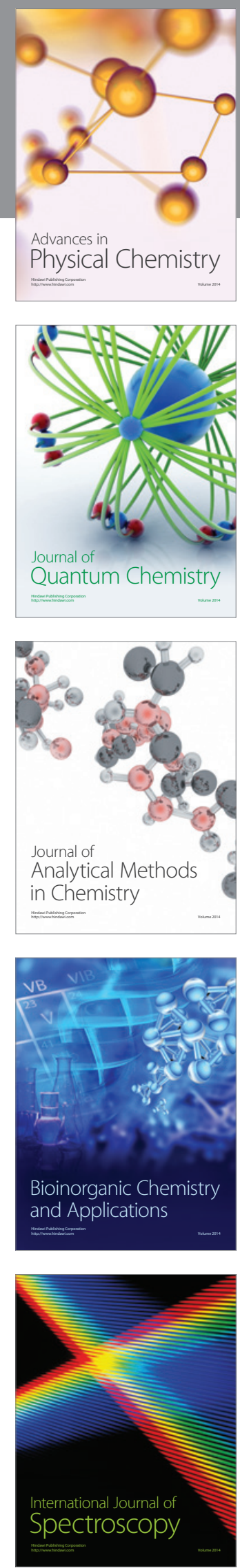